\title{
Automation of oxygen titration in patients with acute respiratory distress at the emergency department. A multicentric international randomised controlled study
}

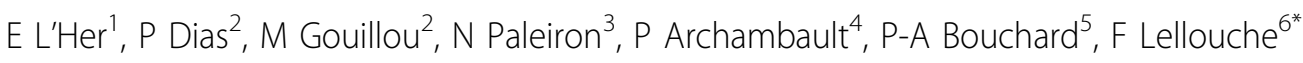 \\ From ESICM LIVES 2015 \\ Berlin, Germany. 3-7 October 2015
}

\section{Introduction}

Oxygen therapy is commonly administered in critical care and emergency medicine. Its benefits are well known but potential side-effects may be underestimated. Compliance to recommendations remains dependent on staff workload. We developed $\mathrm{FreeO}_{2}$, an innovative device that automatically titrates oxygen flow delivered through nasal cannulas or masks to maintain the patients in the $\mathrm{SpO}_{2}$ target set by the clinician ${ }^{1}$.

\section{Objectives}

To compare FreeO $\mathrm{O}_{2}$ with oxygen manual adjustment, in patient admitted to the emergency department (ED) for acute respiratory failure (ARF).

\section{Methods}

We conducted a multicentre randomized controlled study. Inclusion criteria were: admission to ED for ARF requiring $\mathrm{O}_{2} \geq 3 \mathrm{~L} / \mathrm{min}$. Main exclusion criteria were: $\mathrm{O}_{2} \geq 15 \mathrm{~L} / \mathrm{min}$, immediate need for ventilatory support. After inclusion, patients were randomized to either $\mathrm{FreeO}_{2}$ or conventional $\mathrm{O}_{2}$ manual adjustment during 3 hours. The randomization was web-based and stratified for the type of respiratory failure (hypoxemia/hypercapnia) and for the centre. Primary outcome was the \% of time with $\mathrm{SpO}_{2}$ within the predefined target (92-96\% for hypoxemic patients; $88-92 \%$ for hypercapnic patients). Secondary endpoints were: frequency of severe hypoxemia $\left(\mathrm{SpO}_{2}<85 \%\right)$ and hyperoxia $\left(\mathrm{SpO}_{2}>98 \%\right)$, partial or complete oxygen

\footnotetext{
${ }^{6}$ Institut Universitaire de Cardiologie et de Pneumologie de Québec, LacBeauport, Canada

Full list of author information is available at the end of the article
}

weaning at the $\mathrm{ED}$, total $\mathrm{O}_{2}$ duration, ventilator support use, ICU admissions, ICU and hospital LOS.

\section{Results}

187 patients were randomized (93 $\mathrm{FreeO}_{2}$ and 94 Manual). Baseline physiological characteristics were similar in the 2 groups: age $=76 \pm 12 \mathrm{yrs}$., $35 \%$ of COPD patients; mean $\mathrm{O}_{2}$ flow at inclusion was $5.8 \pm 3.1 \mathrm{~L} / \mathrm{min}$. No serious adverse events related to the protocol or device was recorded. The percentage of time within the $\mathrm{SpO}_{2}$ target was $81 \pm 21 \%$ in the $\mathrm{FreeO}_{2}$ arm and $51 \pm 30 \%$ in the Manual arm $(P<0.001)$. Percentage of time with severe hypoxemia and with hyperoxia were significantly lower with $\mathrm{FreeO}_{2}(\mathrm{P}<0.001)$. The percentage of patients with $\mathrm{O}_{2}$ flow reduction of more than $50 \%$ during the 3 hours of the study was $39 \%$ with $\mathrm{FreeO}_{2}$ vs $19 \%$ in the Manual arm $(\mathrm{P}=0.011)$. Percentage of $\mathrm{O}_{2}$ weaning at the end of the study (3h) was $4.3 \%$ in the $\mathrm{FreeO}_{2}$ arm vs. $14.1 \%$ in the Manual arm; p $<0.001$. Significantly less patients in the hypercapnic subgroup were transferred in the ICU, overall $\mathrm{O}_{2}$ administration and hospital LOS were significantly reduced in the non-adjusted analysis $(9.2 \pm 6.9$ vs $11.1 \pm$ 7.0, $\mathrm{P}=0.01$ ).

\section{Conclusions}

The automation of oxygen therapy with $\mathrm{FreeO}_{2}$ at the ED improves the oxygenation parameters with more time in the specified $\mathrm{SpO}_{2}$ target, less desaturation and less hyperoxia. FreeO $\mathrm{O}_{2}$ may reduce staff workload and improve the compliance to recommendations for oxygen administration with potential related clinical benefits

\section{SpringerOpen ${ }^{\circ}$}

(C) 2015 L'Her et al.; This is an Open Access article distributed under the terms of the Creative Commons Attribution License (http:// creativecommons.org/licenses/by/4.0), which permits unrestricted use, distribution, and reproduction in any medium, provided the original work is properly cited. 


\section{Grant Acknowledgment}

PHRC National 2010 FreeO2 Hypox \#08-12

Grant PSR-SIIRI-MDEIE (Ministry of Finances, Québec)

\section{Authors' details}

${ }^{1}$ CHRU Brest, Brest, France. ${ }^{2}$ CHRU Brest, CIC INSERM 1412, Brest, France. ${ }^{3} \mathrm{HIA}$ Clermont-Tonnerre, Brest, France. ${ }^{4}$ Hôtel Dieu, Lévis, Canada. ${ }^{5}$ Institut Universitaire de Cardiologie et de Pneumologie de Québec, Québec, Canada. ${ }^{6}$ Institut Universitaire de Cardiologie et de Pneumologie de Québec, Lac-

Beauport, Canada.

Published: 1 October 2015

\section{Reference}

1. Lellouche F, L'her E: Automated oxygen flow titration to maintain constant oxygenation. Respir Care 2012, 57(8):1254-1262.

doi:10.1186/2197-425X-3-S1-A424

Cite this article as: L'Her et al: Automation of oxygen titration in

patients with acute respiratory distress at the emergency department.

A multicentric international randomised controlled study. Intensive Care Medicine Experimental 2015 3(Suppl 1):A424.

\section{Submit your manuscript to a SpringerOpen ${ }^{\mathcal{O}}$ journal and benefit from:}

- Convenient online submission

- Rigorous peer review

- Immediate publication on acceptance

- Open access: articles freely available online

- High visibility within the field

- Retaining the copyright to your article 